\title{
Editorials
}

\section{Managing older people's alcohol misuse in primary care}

It would be too optimistic to suppose that the relative under-representation of subjects in the older age groups ... is just explained by older people having generally got the treatment they required ... it seems likely that this finding is in part a hint of the diminished life expectancy of the alcoholic.' (Professor Griffith Edwards, 19671)

Over the past 50 years, increased life expectancy has changed the demographic structure of the UK population. This has had profound consequences for corresponding changes in lifestyle and health. Four years ago, we highlighted the alarming trend of rising alcohol misuse among older people in the UK. ${ }^{2}$ Even using more refined ways of measuring the burden of alcohol-related illness, hospital admissions that are wholly attributable to alcohol for people aged $\geq 65$ years in England have nearly doubled over the past 6 years (Figure 1). ${ }^{3} \mathrm{~A}$ rise of over $>90 \%$ in the number of admissions for people aged $\geq 65$ years far outstrips the rise in overall numbers of people in this age group. ${ }^{4}$ Therefore, strategies are clearly needed to address alcohol misuse by identifying and targeting appropriate areas for clinical intervention

\section{BARRIERS TO ASSESSING ALCOHOL USE AND MISUSE}

Alcohol use and misuse in older people is easy to overlook in primary care settings. There may be unintentional ageism by carers, where sleep problems are attributed to someone being 'always a poor sleeper', or appetite problems labelled as a lifelong fastidiousness with food. Older people may be stigmatised and under-report their alcohol intake for fear of being labelled 'alcoholic'. In busy patient encounters, clinical evidence of alcohol misuse such as lack of energy and changes in mood may be misattributed to depression or physical illness. Additionally, stereotyping may mean overlooking substance misuse in older women. ${ }^{5}$

Although there may still be scope for opportunistic screening, other factors limiting access to treatment also exist. These include time constraints/competing demands and insufficient training. Even if older patients experience problems from their alcohol misuse, there may be a degree of therapeutic nihilism based on a perceived limited evidence base for treatment. All

"The provision of integrated care is central to improving health and social outcomes, and GPs are often at the centre of delivering such care for older people with alcohol misuse; also drawing upon expertise from old age, addiction and geriatric services.

this is compounded by conventional rating scales having little relevance to older people, where alcohol-related harm may occur at lower levels of intake, ${ }^{6}$ and where associated problems reflect a very different range of psychosocial difficulties.

Therefore, barriers to assessing alcohol use and misuse among older patients are substantial and may be preventing the provision of appropriate care for these patients.

\section{MOVING TO AN INTEGRATED CARE MODEL}

GPs have a central role to play in assessment (including screening) and brief intervention, as well as working with housing, social services and voluntary agencies to improve health and social care. However, there is also scope for developing further competencies such as adopting a nonconfrontational approach to assessment that is appropriately paced and that takes into account depression, loneliness, and loss.

Age-appropriate screening instruments such as the Short Michigan Alcoholism Screening Test - Geriatric version [SMAST-G] show the greatest promise in detecting alcohol misuse, asking questions such as do you drink to 'calm nerves', 'take mind off problems', and 'after a significant loss'.?

A positive screening result can then be followed up by using a Brief Intervention, which can take less than 5 minutes. This involves giving information, advice, and encouragement to the patient to consider the positives and negatives of their drinking behaviour. It also includes support and help for the patient if they do decide they want to cut down on their drinking. They are usually 'opportunistic' in that they are administered to patients who have not attended a consultation specifically to discuss their drinking. This is a likely scenario for older people who are at increasing or high risk of alcohol misuse. For dependent drinkers, secondary care services may be required.

\section{THE INTERFACE WITH OLD AGE PSYCHIATRY, ADDICTION, AND GERIATRIC SERVICES}

Community old age psychiatry services lack the expertise to assess and treat older people with alcohol misuse, but have the advantage of operating a home-based model of care. Delivering a service for older people with alcohol misuse remains an aspiration, although the development of knowledge, skills, and attitudes that bridge the divide between older people's mental health and primary care shows promise in providing seamless care from assessment to care planning and intervention. ${ }^{5.9}$ Much of this service delivery has been based around older people whose alcohol misuse accompanies other mental disorders such as anxiety, depression, and cognitive impairment. Offering a multidisciplinary approach to assessment and care planning has shown outcomes such as rates of controlled drinking and abstinence that are comparable to those of mainstream addiction services. ${ }^{10}$

Addiction services have much to offer in terms of supervised treatment at home or admission for detoxification under medical supervision. Treating older people with medication is a subtly balanced judgement taking account of comorbidities, pharmacological treatments for these, interactions of prescribed medications with each other, and of course, with alcohol. After the acute phase, primary care may support more intensive psychological treatments such as motivational interviewing and cognitive behavioural interventions. In this way, patients can explore other strategies to cope without drink. 


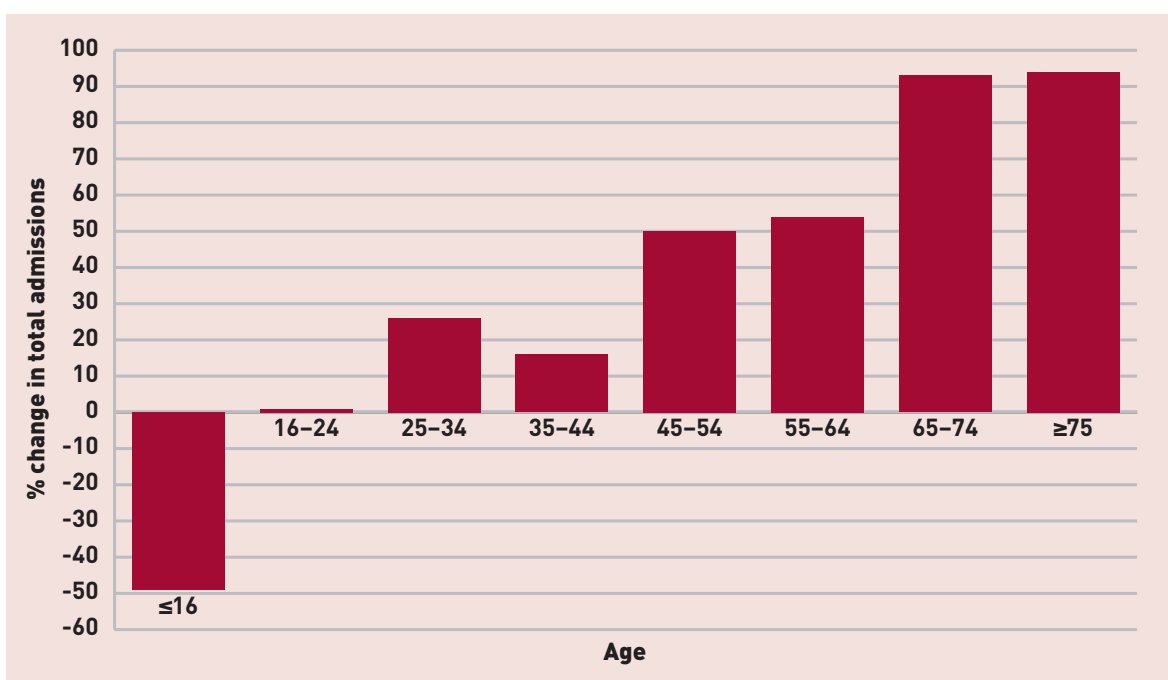

Figure 1. Trends in alcohol specific admissions to hospitals in England.

Of course, the GP is in a prime position to monitor the patient regularly, and even if the patient has stopped alcohol use, there may be the temptation to substitute with other substances such as prescribed medications.

The primary care team is likely to have a broad understanding of the patient's attitudes to interventions and to become aware of any changes early on (bereavement or retirement, for example, or health concerns such as memory deterioration), which may precipitate, initiate or escalate drinking. The delivery of a Brief Intervention in primary care to change drinking behaviour has been shown to save up to $€ 10$ for every €1 spent. "1 Just as alcohol problems may be attributed to physical illness or "normal ageing', so may physical problems be attributed to alcohol use and misuse. The physical consequences of alcohol misuse are legion and affect almost all systems of the body. Alcohol misuse may be a contributory factor to all of the geriatric giants: impaired intellectual function, immobility, instability, and incontinence. Maximising physical health is a vital component in helping patients (and carers), and assistance from memory clinics, falls and/or continence services should always be considered.

The provision of integrated care is central to improving health and social outcomes, and GPs are often at the centre of delivering such care for older people with alcohol misuse; also drawing upon expertise from old age, addiction and geriatric services.

\section{NEW WAYS OF WORKING THAT WORK BETTER}

Older people whose alcohol misuse is masked by other medical and mental health problems, rationalised or denied by patients, and hidden by drinking in their own homes can be detected by an approach connecting a non-judgemental approach with one that is problem based. This can then be combined with measuring the quantity and frequency of drinking behaviour. Incorporating this approach into routine consultations is invaluable, as is the use of a Brief Intervention. Even beyond this stage of treatment, addiction, older people's mental health and geriatric services have much to offer for an increasing population of older people with a growing need for timely assessment and intervention for an expanding problem.

There are considerable opportunities for GPs to improve the quality of life for older people with alcohol misuse. This can be achieved by the use of both planned and opportunistic screening as part of a general health review, particularly when accompanied by mental disorders, as well as coexisting alcohol-related physical problems. Improving referral to secondary care services will also help provide a seamless approach to improving care for an older population that will continue to weigh heavily on primary care.

\section{Rahul Rao,}

Consultant Old Age Psychiatrist, Department of Old Age Psychiatry, South London and Maudsley NHS Foundation Trust, London; and Visiting Lecturer, Institute of Psychiatry, Psychology and Neurology, London.

\section{Ilana B Crome,}

Emeritus Professor, Keele University, Honorary Professor, Queen Mary University of London; and Visiting Professor, St George's University of London.

\section{Peter Crome}

Honorary Professor, Department of Primary Care and Population Health, University College London;

\section{ADDRESS FOR CORRESPONDENCE}

\section{Rahul Rao}

Southwark Community Team for Older People, South London and Maudsley NHS Foundation Trust Ground Floor, 63-65 Marina House, Denmark Hill, London SE5 8RS.

\section{E-mail: tony.raolakcl.ac.uk}

and Emeritus Professor of Geriatric Medicine, Keele University, Keele.

\section{Provenance}

Commissioned; externally peer reviewed.

\section{DOI: 10.3399/bjgp16X683041}

\section{REFERENCES}

1. Edwards G, Kellog-Fisher M, Hawker, et al. Clients of alcoholism information centres. BMJ 1967; 4 (5575): 346-349.

2. Crome I, Dar K, Janikiewicz S, et al. Our invisible addicts. First report of the older persons' substance misuse working group of the Royal College of Psychiatrists. College Report CR165. London: Royal College of Psychiatrists, 2011.

3. Lifestyles Statistics Team. Health and Social Care Information Centre. Statistics on alcohol. England, 2015. London: HSCIC, 2015. http:// www.hscic.gov.uk/catalogue/PUB17712/alceng-2015-rep.pdf laccessed 16 Nov 2015).

4. Rao, T. Trends in alcohol related admissions for older people with mental health problems: 2002 to 2012. London: Alcohol Concern, 2013. http://www.alcoholconcern.org.uk/wp-content/ uploads/woocommerce_uploads/2014/10/ Alcohol-Concern-Briefing-alcohol-and-olderpeople.pdf (accessed 16 Nov 2015).

5. Crome I, Wu LT, Rao RT, Crome P. Substance use and older people. London: John Wiley \& Sons, 2015

6. Crome I, LI TK, Rao R et al. Alcohol limits in older people. Addiction 2012; 107(9):1541-1543.

7. Blow FC, Gillespie BW, Barry KL, et al. Brief screening for alcohol problems in the elderly populations using the Short Michigan Alcoholism Screening Test-Geriatric Version (SMAST-G). Alcohol Clin Exp Res 1998; 22 (Suppl): 131A.

8. Fleming MF, Manwell LB, Barry KL, et al. Brief physician advice for alcohol problems in older adults: a randomized community-based trial. $J$ Fam Pract 1999; 48(5): 378-384.

9. Rao R, Shanks A. Development and implementation of a dual diagnosis strategy for older people in south east London. Adv Dual Diag 2011; 4: 28-35.

10. Rao R. Outcomes from liaison psychiatry referrals for older people with alcohol use disorders in the UK. Ment Health Subst Use 2013; 6(4): 362-368.

11. Ubido J, Lewis, C, Holford R, et al. Prevention programmes cost-effectiveness review: alcohol. Observatory Report Series no. 84). Liverpool: Public Health Observatory, 2010. 